\title{
Osteopontin accumulates in basal deposits of human eyes with age-related macular degeneration and may serve as a biomarker of aging
}

\author{
Michael Lekwuwa ${ }^{1,3}$, Mayur Choudhary ${ }^{1,3}$, Eleonora M. Lad ${ }^{1}$ and Goldis Malek ${ }^{1,2} \bowtie$
}

(c) The Author(s) 2021

A common clinical phenotype of several neurodegenerative and systemic disorders including Alzheimer's disease and atherosclerosis is the abnormal accumulation of extracellular material, which interferes with routine cellular functions. Similarly, patients with age-related macular degeneration (AMD), the leading cause of vision loss among the aged population, present with extracellular lipid- and protein-filled basal deposits in the back of the eye. While the exact mechanism of growth and formation of these deposits is poorly understood, much has been learned from investigating their composition, providing critical insights into AMD pathogenesis, prevention, and therapeutics. We identified human osteopontin (OPN), a phosphoprotein expressed in a variety of tissues in the body, as a newly discovered component of basal deposits in AMD patients, with a distinctive punctate staining pattern. OPN expression within these lesions, which are associated with AMD disease progression, were found to co-localize with abnormal calcium deposition. Additionally, OPN puncta colocalized with an AMD risk-associated complement pathway protein, but not with apolipoprotein E or vitronectin, two other well-established basal deposit components. Mechanistically, we found that retinal pigment epithelial cells, cells vulnerable in AMD, will secrete OPN into the extracellular space, under oxidative stress conditions, supporting OPN biosynthesis locally within the outer retina. Finally, we report that OPN levels in plasma of aged (nonAMD) human donors were significantly higher than levels in young (non-AMD) donors, but were not significantly different from donors with the different clinical subtypes of AMD. Collectively, our study defines the expression pattern of OPN in the posterior pole as a function of disease, and its local expression as a potential histopathologic biomarker of AMD.

Modern Pathology (2022) 35:165-176; https://doi.org/10.1038/s41379-021-00887-7

\section{INTRODUCTION}

Age-related macular degeneration (AMD), is an ocular neurodegenerative disease of aging, and the most common cause of irreversible blindness in the elderly in developed countries ${ }^{1-3}$, with consequent detrimental effects on physical and mental health ${ }^{4,5}$. Clinically, the initial stage of AMD development, known as early nonexudative, is characterized by accumulation of lipid- and protein-filled extracellular deposits, basal to the retinal pigment epithelium $(\mathrm{RPE})^{6-8}$, a cuboidal epithelial cell layer that serves as support for everyday functions of the overlying neurosensory retina ${ }^{9,10}$. The basal deposit family includes drusen, basal laminar, and basal linear deposits, all of which are detrimental to RPE function, enable RPE and photoreceptor cell atrophy, and importantly lead to progressive and more severe visual deterioration in the form of advanced nonexudative $A M D$, also known as geographic atrophy $(G A)^{11-13}$ and the advanced "wet" or neovascular form of AMD ${ }^{14-16}$. Due to the increase in life expectancy, it is predicted that the prevalence of $A M D$ in the aged population will be an even greater health problem in the near future ${ }^{17}$, thus necessitating further investigations into the composition of basal deposits and evolution of the early events in AMD development.
Basal deposit composition along with genetic risk factors identified from epidemiological and genome wide association studies, implicate multiple pathogenic pathways associated with AMD development and progression, underscoring the multifactorial nature of the disease $e^{18-20}$. Components of basal deposits identified to date via proteomics and histological methods include factors involved in lipid metabolism and transport, glycoproteins, mineral constituents, and extracellular matrix molecules to name a few ${ }^{21-24}$. Based on these findings, chronic inflammation has emerged as a pathogenic mechanism that may contribute to formation and accumulation of basal deposits, a thought given further credence by the observed localization of several factors associated with immune regulation, including members of the complement pathway, within these lipid- and protein-rich foci ${ }^{25-28}$.

Osteopontin (OPN) is a matricellular protein expressed by a number of cell types throughout the body, including but not limited to macrophages, endothelial cells, epithelial cells, and fibroblasts ${ }^{29-34}$. In the eye, OPN has been reported to be expressed in retinal ganglion, microglial, RPE and choroidal endothelial cells $s^{35-39}$. The regulation of osteopontin, which is encoded by the gene secreted phosphoprotein 1 (SPP1), is still

${ }^{1}$ Duke Eye Center, Department of Ophthalmology, Duke University School of Medicine, Durham, NC, USA. ${ }^{2}$ Department of Pathology, Duke University School of Medicine, Durham, NC, USA. ${ }^{3}$ These authors contributed equally: Michael Lekwuwa, Mayur Choudhary. ${ }^{\varpi_{\text {email: }}}$ gmalek@duke.edu 
poorly understood, but studies have indicated that it plays a critical role in several physiologic and pathologic events including mineralization, apoptosis, angiogenesis, cellular remodeling, and inflammation ${ }^{40-44}$. From a disease perspective, OPN has been investigated in neurodegenerative diseases that share common pathogenic pathways with AMD, including Alzheimer's disease, atherosclerosis, and multiple sclerosis, and found to be differentially regulated in response to either inflammation or injury ${ }^{45}$. Specifically, OPN has been shown to stimulate the expression of pro-inflammatory mediators, triggering relapses in multiple sclerosis ${ }^{46}$, and an increase in inflammatory cells within atherosclerotic plaques ${ }^{47-49}$. Paradoxically, OPN may also mediate antiinflammatory effects by attenuating oxidative stress through its repression of inducible nitric oxide synthase ${ }^{50-52}$. OPN is also elevated in the cerebral spinal fluid of Alzheimer's disease patients $^{53}$ suggesting that it may act as a biomarker for the disease. At the molecular level, OPN binds to integrins and CD44 variants on the cell surface to influence cell survival and apoptosis, inflammation, microcalcification, cell attachment and migration, and chemotaxis after an injury ${ }^{31,46,54}$, cellular events also involved to different degrees in AMD development ${ }^{7,13}$.

Given the association between OPN in neurodegenerative diseases that share common pathogenic pathways with AMD as well as OPN's asserted role in inflammation and macrophage recruitment, herein the expression of OPN was investigated in the context of the pathobiology of AMD. Localization and expression of OPN in eyes from normal and AMD donor tissue were investigated. Mechanistically, the impact of AMD-relevant stressors on extracellular OPN secretion from human RPE cells, cells vulnerable in AMD, was evaluated. Finally, given that age is a major risk factor for AMD, OPN levels in the plasma from young versus old non-AMD donors, were measured along with circulating levels of OPN as a function of clinical stages of AMD. We report that while age effects circulating levels of OPN, local OPN expression correlates with calcified, large drusen, and serves as a histopathologic biomarker of early AMD.

\section{METHODS \\ Human ocular tissues}

Use of human donor eyes for research was approved by the Duke University Institutional Review Board (Exempt Review), and collected by either BioSight, the North Carolina Organ Donor and Eye Bank Inc., the Alabama Eye Bank, or through Duke Department of Pathology. Eyes used for harvesting ocular cells were processed on ice within $8 \mathrm{~h}$ postmortem, as previously described ${ }^{55-57}$, and included fresh isolation of human RPE cells, retina, and choroid. "Non-AMD" donor eyes did not exhibit evidence of retinal/RPE changes upon postmortem evaluation of the posterior pole under a dissecting microscope with back light illumination (Leica MZ6 Stereomicroscope, Leica Microsystems Inc. Buffalo Grove, IL, USA). For histological studies, donor eyes were also collected from patients diagnosed with AMD, the pathologies of which were confirmed on postmortem evaluation of retinal cross-sections stained with hematoxylin and eosin (Table 1 and Supplementary Fig. $1 ; n=11$ ), with a recorded death to preservation time of 3-44 h. Eyes were preserved by immersion in $4 \%$ paraformaldehyde. Approximately $16 \mathrm{~h}$ later the anterior segments were removed, posterior poles were embedded in paraffin, and sectioned from the superior cup through the optic nerve to the inferior cup in $10 \mu \mathrm{m}$ increments ${ }^{56,58,59}$.

\section{Cell culture lines}

In vitro assays included the use of primary RPE (hRPE) cells harvested from human non-AMD donor eyes $(n=3 ; 48$-year-old male, passages 2-4; 84-year-old male, passage 2-4; and 93-year-old female, passages 4-7), the human derived ARPE19 cell line (passages 26-28), and the macaque derived RF/6A choroidal endothelial cell line (passage 32-35), cultured as previously described $57,59,60$. In vitro experiments were performed on RPE cell cultures grown to a post-confluent state with demonstrated zonula occludens- 1 immunoreactivity in parallel wells ${ }^{55-58}$.

\section{RNA isolation and qPCR}

Total RNA isolated from cultured cells, freshly isolated human RPE cells, retina, and choroid, along with RNA quality assessment, cDNA reverse transcription, and PCR, were completed as previously described ${ }^{55-58}$. The death to preservation time for the human donor tissue was $<8 \mathrm{~h}$. PCR was performed using the Bio-Rad CFX96 Real-time PCR Detection System (BioRad, Hercules, CA). The amplification products of OPN and $36 B 4$ primers obtained after Real time PCR were run on a $1 \%$ agarose gel and visualized with ethidium bromide. Primer sequences used were selected from Primer Bank, http://pga.mgh.harvard.edu/primerbank. The primer sequences are as follows: OPN: Forward-5'-CTCCATTGACTCGAACGACTC-3', Reverse- $5^{\prime}$-CAG GTCTGCGAAACTTCTTAGAT-3', and 36B4: Forward-5'-GGACATGTTGCTGGC CAATAA-3', Reverse-5'-GGGCCCGAGACCAGTGTT-3'.

\section{Protein isolation and western blot protocol}

Protein was isolated from cell culture and human tissue (retina, RPE, and choroid) and total protein was determined using the Pierce BCA Protein Assay Kit (Thermo Fisher Scientific, Waltham, MA), as previously described ${ }^{55}$. The death to preservation time for the human donor tissue was $<8 \mathrm{~h}$. Western blotting was performed as previously described with the housekeeping protein, beta-actin (Table 2), serving as a loading control ${ }^{58}$.

\section{Immunohistochemistry}

Protein localization in paraffin sections probed with antibodies (Table 2), was performed as previously described ${ }^{55,59,60}$. Nonspecific immunostaining in sections was blocked with normal serum (Jackson Immunoresearch, West Grove, PA, USA) appropriate to the secondary antibody species. Secondary antibodies were conjugated to AlexaFluor 568 or 488 (Invitrogen, Carlsbad, CA). Control slides containing sequential sections were probed with nonimmune serum and buffer without primary antibody. Paraffin sections were subjected to deparaffinization and antigen retrieval to restore the immunoreactivity of epitopes, prior to initiation of the immunohistochemistry staining procedure ${ }^{59}$. Images were visualized and collected using a Nikon C2si confocal microscope Nikon Instruments Inc., Melville, NY, and processed using the Nikon Elements software (AR 4.50.00 64-bit) to display maximum intensity projection.

\section{Peptide competition immunofluorescence assay}

To further demonstrate specificity of the OPN antibody, immunofluorescence staining was performed in the presence of recombinant human peptide (rhOPN). Briefly, the OPN antibody was incubated for $24 \mathrm{~h}$ with rhOPN (\#1433-OP; R\&D systems, Minneapolis, MN) at two different antibody-to-peptide ratios (1:5 and 1:10), followed by immunostaining as described. The sections were also subjected to autofluorescence quenching by Vector ${ }^{\circ}$ TrueVIEW ${ }^{\mathscr{*}}$ Autofluorescence Quenching Kit (Vector Laboratories, Inc. Burlingame, CA) to reduce RPE autofluorescence.

\section{OPN immunoreactivity quantification}

Immunohistological images of OPN stained retinal cross-sections were processed using Adobe photoshop CC to measure the diameter (largest dimension) of the individual OPN puncta in each druse. The diameter of a total of 79 OPN positive puncta ( $n=4$ slides from $n=3$ donors) was measured and reported as $\mu \mathrm{m}$. Slides probed with the OPN antibody were also scanned and the percentage of total number of drusen containing OPN positive puncta was also calculated $(n=1$ slide from $n=7$ donors).

\section{Von-Kossa histochemistry stain}

To stain for evidence of calcification in paraffin sections, the "Von-Kossa method for calcium" kit (Polysciences Inc: 3\% Silver nitrate, 5\% Sodium thiosulfate, and Nuclear fast red), an indirect histochemical stain, was used according to manufacturer's protocol.

\section{Cell culture}

In a T25 flask, $2 \times 10^{5}$ human primary RPE (hRPE) cells/well were plated in DMEM/F12 medium (Thermo Fisher Scientific) supplemented with $10 \%$ fetal bovine serum (FBS; Sigma, St. Louis, MO). Post confluence, cells were serumstarved (1\% FBS-DMEM/F12) for $24 \mathrm{~h}$ and treated with the following AMDrelevant stressors: $5 \%$ Cigarette-Smoke Extract $(\mathrm{CSE})^{55,61}, 50 \mu \mathrm{M}$ hydroquinone ( $\mathrm{HQ}$; Sigma); $50 \mu \mathrm{g} / \mathrm{mL}$ recombinant OPN (R\&D Systems), $20 \mu \mathrm{M}$ Arachidonic acid (AA; MP Biomedicals, USA), $1 \mu \mathrm{g} / \mathrm{mL}$ Docosahexaenoic Acid 

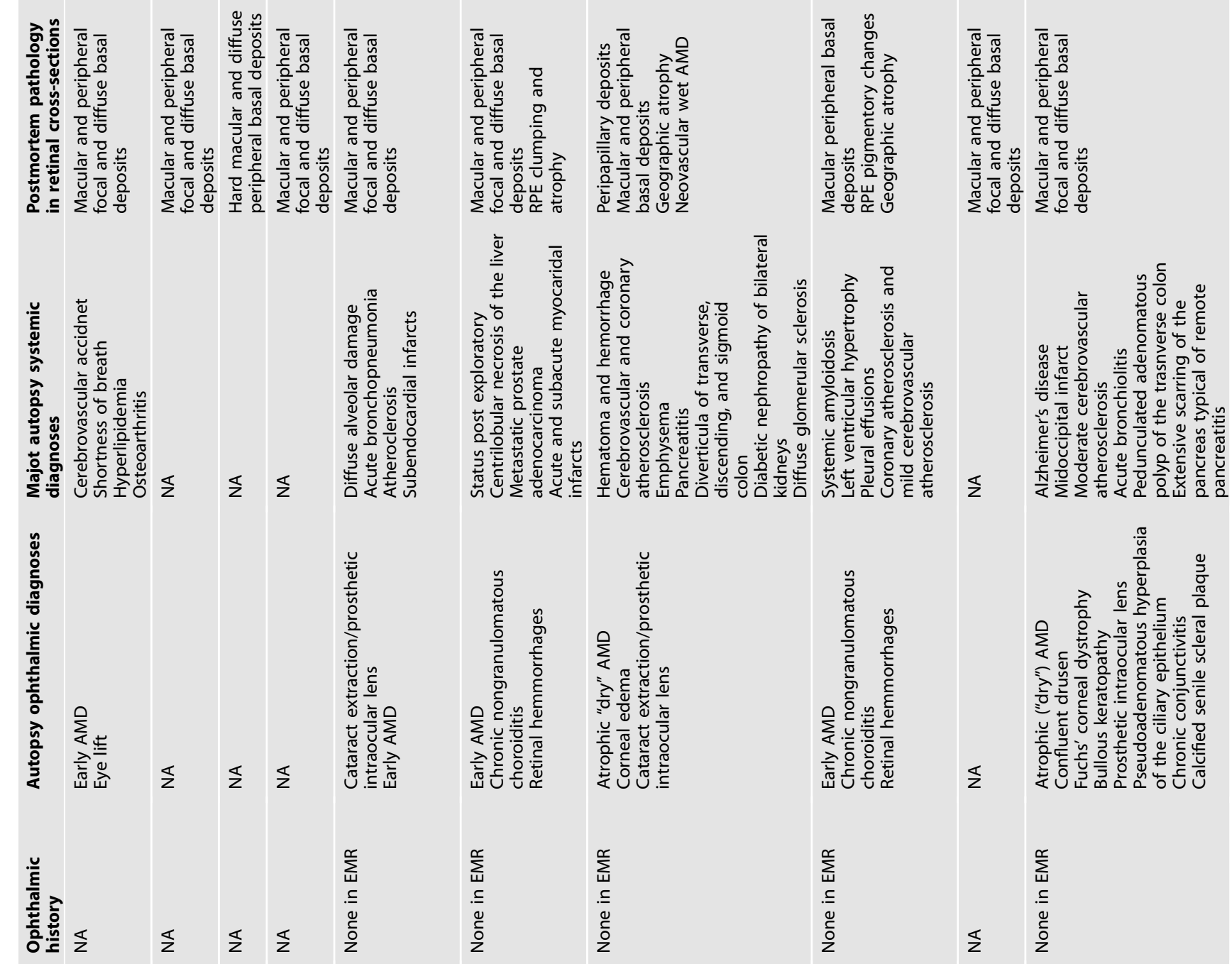

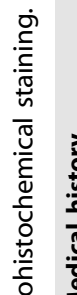
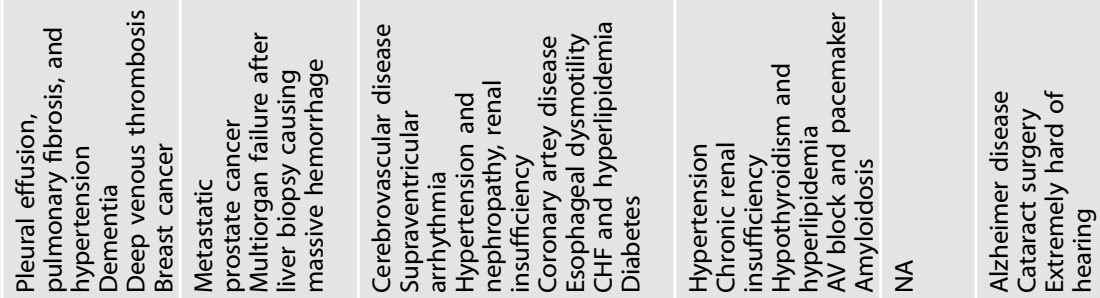

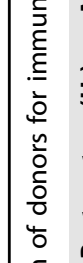

竞

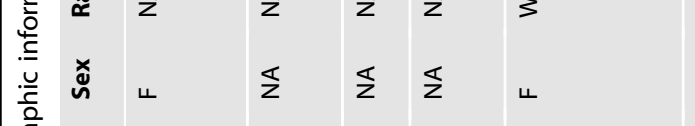

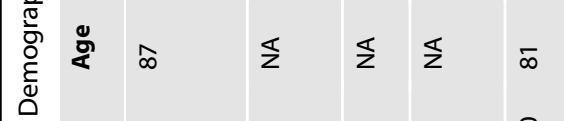

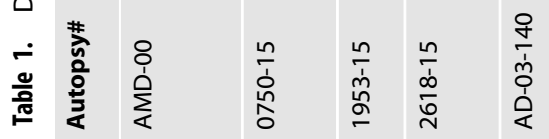

$\stackrel{m}{i}$

$\approx$

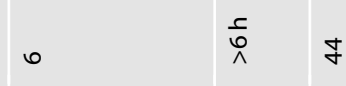

$\infty \quad 3$

$\infty \quad \Sigma \quad 3$

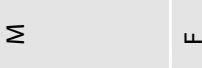

$\Sigma$

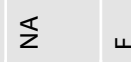

6 क

$\infty$

늠

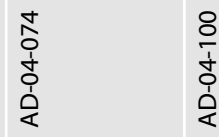

$m$
$\frac{m}{+}$
$\dot{c}$
$\dot{1}$

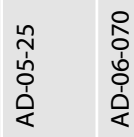


Table 2. Antibodies/stains used for western blot, immunofluorescence, and histology.

\begin{tabular}{|c|c|c|c|}
\hline Antibody/stain & Source & Dilution & Catalog\# \\
\hline $\begin{array}{l}\text { Alpha-Smooth muscle } \\
\text { actin }(\alpha S M A)\end{array}$ & Sigma-Aldrich & $1: 5000$ & A5228 \\
\hline Apolipoprotein E (APOE) & Millipore & $1: 500$ & AB947 \\
\hline Beta-Actin & SCBT & 1:5000 & sc-47778 \\
\hline CD31 & Dako & $1: 50$ & M0823 \\
\hline $\begin{array}{l}\text { Complement factor } \\
\text { H (CFH) }\end{array}$ & Quidel & $1: 200$ & A312 \\
\hline $\begin{array}{l}\text { Hoechst } 33258 \\
\text { pentahydrate }\end{array}$ & Invitrogen & $2 \mu \mathrm{g} / \mathrm{ml}$ & H3569 \\
\hline Iba1 & Wako & $1: 200$ & 019-19741 \\
\hline Osteopontin (OPN) & Sigma-Aldrich & $1: 200$ & O7264 \\
\hline Vitronectin (VTN) & Santa-Cruz & $1: 500$ & SC-74484 \\
\hline $\begin{array}{l}\text { Von-Kossa method for } \\
\text { calcium kit }\end{array}$ & Polysciences & & 24633-1 \\
\hline
\end{tabular}

(DHA; Sigma-Aldrich,), $1 \mathrm{mM}$ vascular endothelial growth factor (VEGF; R\&D Systems), $50 \mu \mathrm{g} / \mathrm{mL}$ oxidized low-density lipoproteins (oxLDL; Invitrogen, Eugene Oregon), $50 \mu \mathrm{g} / \mathrm{mL} \mathrm{LDL}$ (Invitrogen), and $100 \mu \mathrm{M}$ sodium iodate (NalO3; Sigma-Aldrich) for $48 \mathrm{~h}$. The media was collected and secreted proteins from human RPE cells were concentrated using the Pierce Protein Concentrator Kit (Thermo Scientific), followed by assessment of protein levels using the Pierce BCA Protein Assay kit, prior to measuring OPN levels using the Quantikine Human OPN ELISA kit (R\&D Systems) according to the manufacturer's protocol.

\section{Cell viability}

hRPE cultures were visualized using a Zeiss Observer D1 microscope (Carl Zeiss Microscopy LLC, White Plains, NY) after $48 \mathrm{~h}$ treatment with AMDrelevant stressors as described above, then harvested to assess cell viability using CellTiter-Blue (Promega, Madison, WI), according to the manufacturer's protocol. The results were reported as relative fluorescence (excitation: $560 \mathrm{~nm}$, emission: $590 \mathrm{~nm}$ ).

\section{OPN human donor plasma quantification}

Human donor (Table 3) blood samples were collected from young (20-28-year-old) and old (62-86-year-old) non-AMD individuals and AMD patients diagnosed with early AMD (drusen diameter 64-124 $\mu \mathrm{m}$ ); intermediate AMD (drusen diameter $>125 \mu \mathrm{m}$ and no evidence of GA), or neovascular AMD under a Duke approved Institutional Review Board protocol (\# Pro00063921) in glass tubes containing heparin or EDTA as an anticoagulant. Plasma samples were centrifuged $(1000 \times g)$ for $15 \mathrm{~min}$ at $4{ }^{\circ} \mathrm{C}$, immediately aliquoted, and transferred into new Eppendorf tubes for storage at $-80^{\circ} \mathrm{C}$. OPN levels were determined and quantified using the Quantikine Human OPN ELISA kit according to the manufacturer's protocol (R\&D Systems). Optical coherence tomography (OCT) and fundus images were recorded in the clinic as part of the patient's routine clinical exam.

\section{Statistical methods and rigor}

Statistical methods for data analysis included two-tailed Student's $t$ test and two-way ANOVA, followed by Sidak's multiple comparison test using GraphPad Prism (Version 9.0.0 for Windows, Graphpad Software LLC., San Diego, CA). Values were considered statistically significant at $p<$ 0.05 . For the in vitro experiments, the technical samples were run in triplicate and biological experiments were performed a minimum of three times.

\section{RESULTS}

OPN is expressed in the posterior human retina

To identify ocular cells and tissue compartments that express OPN, gene expression was examined in cells isolated from the posterior retina, including cultured hRPE cells, the human derived ARPE19 
Table 3. Demographic information of plasma donors.

\begin{tabular}{|c|c|c|c|c|c|}
\hline & Study group & Age & Gender & Race & Ethnicity \\
\hline 1 & Non-AMD (Young) & 20 & $\mathrm{~F}$ & African American & Not Hispanic or Latino \\
\hline 2 & Non-AMD (Young) & 24 & $\mathrm{~F}$ & White & Not Hispanic or Latino \\
\hline 3 & Non-AMD (Young) & 25 & M & White & Not Hispanic or Latino \\
\hline 4 & Non-AMD (Young) & 28 & M & White & Unknown \\
\hline 5 & Non-AMD (Young) & 28 & $\mathrm{~F}$ & Asian & Not Hispanic or Latino \\
\hline 1 & Non-AMD (Aged) & 62 & M & White & Not Hispanic or Latino \\
\hline 4 & Non-AMD (Aged) & 66 & $\mathrm{~F}$ & White & Not Hispanic or Latino \\
\hline 5 & Non-AMD (Aged) & 75 & Unknown & Unknown & Unknown \\
\hline 6 & Non-AMD (Aged) & 78 & $\mathrm{~F}$ & White & Not Hispanic or Latino \\
\hline 7 & Non-AMD (Aged) & 79 & Unknown & Unknown & Not Hispanic or Latino \\
\hline 12 & Non-AMD (Aged) & Unknown & M & White & Not Hispanic or Latino \\
\hline 1 & Early-intermediate AMD & 59 & $\mathrm{~F}$ & White & Not Hispanic or Latino \\
\hline 2 & Early-intermediate AMD & 59 & M & White & Not Hispanic or Latino \\
\hline 3 & Early-intermediate AMD & 69 & $\mathrm{~F}$ & White & Not Hispanic or Latino \\
\hline 4 & Early-intermediate AMD & 76 & $\mathrm{~F}$ & White & Not Hispanic or Latino \\
\hline 5 & Early-intermediate AMD & 78 & $\mathrm{~F}$ & White & Not Hispanic or Latino \\
\hline 6 & Early-intermediate AMD & 84 & $\mathrm{~F}$ & White & Not Hispanic or Latino \\
\hline 1 & Late AMD & 60 & Unknown & Unknown & Unknown \\
\hline 2 & Late AMD & 66 & M & White & Not Hispanic or Latino \\
\hline 3 & Late AMD & 66 & $\mathrm{~F}$ & White & Not Hispanic or Latino \\
\hline 10 & Late AMD & 73 & $M$ & White & Not Hispanic or Latino \\
\hline 11 & Late AMD & 73 & $\mathrm{~F}$ & White & Not Hispanic or Latino \\
\hline 12 & Late AMD & 75 & $\mathrm{~F}$ & White & Not Hispanic or Latino \\
\hline 13 & Late AMD & 77 & M & White & Not Hispanic or Latino \\
\hline 14 & Late AMD & 78 & M & White & Not Hispanic or Latino \\
\hline 1 & CNV & 65 & $\mathrm{~F}$ & White & Not Hispanic or Latino \\
\hline 2 & CNV & 68 & $\mathrm{~F}$ & White & Not Hispanic or Latino \\
\hline 3 & CNV & 69 & $\mathrm{~F}$ & White & Not Hispanic or Latino \\
\hline 4 & CNV & 77 & $\mathrm{~F}$ & White & Not Hispanic or Latino \\
\hline 5 & CNV & 77 & $\mathrm{~F}$ & White & Not Hispanic or Latino \\
\hline 6 & CNV & 78 & $\mathrm{~F}$ & White & Not Hispanic or Latino \\
\hline 7 & CNV & 81 & $\mathrm{~F}$ & White & Not Hispanic or Latino \\
\hline
\end{tabular}

cell line, and the macaque derived RF/6A choroidal endothelial cell line, in addition to freshly isolated RPE, retina, and choroid from human donor eyes. We observed expression of OPN mRNA (SPP1) and protein in the in vitro cell model systems as well as in freshly isolated human tissue (Fig. 1A, B), confirming that retina, RPE, and choroid tissue in the posterior pole express OPN and these tissues may potentially act as a local source of OPN. Additionally, we observed protein immunolocalization of OPN in retinal crosssections from non-AMD donor eyes, throughout the retinal ganglion cell layer, nerve fiber layer, inner plexiform layer of the retina, the RPE, and cells within the choroid (Fig. 1C). Specificity of the anti-OPN antibody was confirmed via western blot evaluation of OPN recombinant protein and immunohistochemistry competition assays (Supplementary Figs. 2, 3). 
A

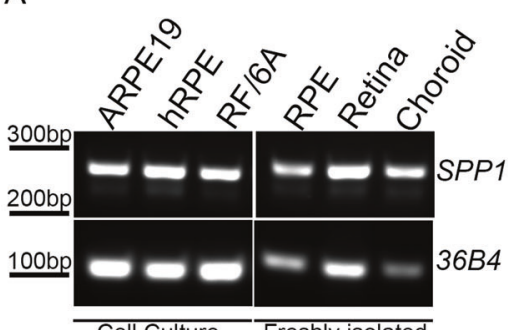

Cell Culture
B
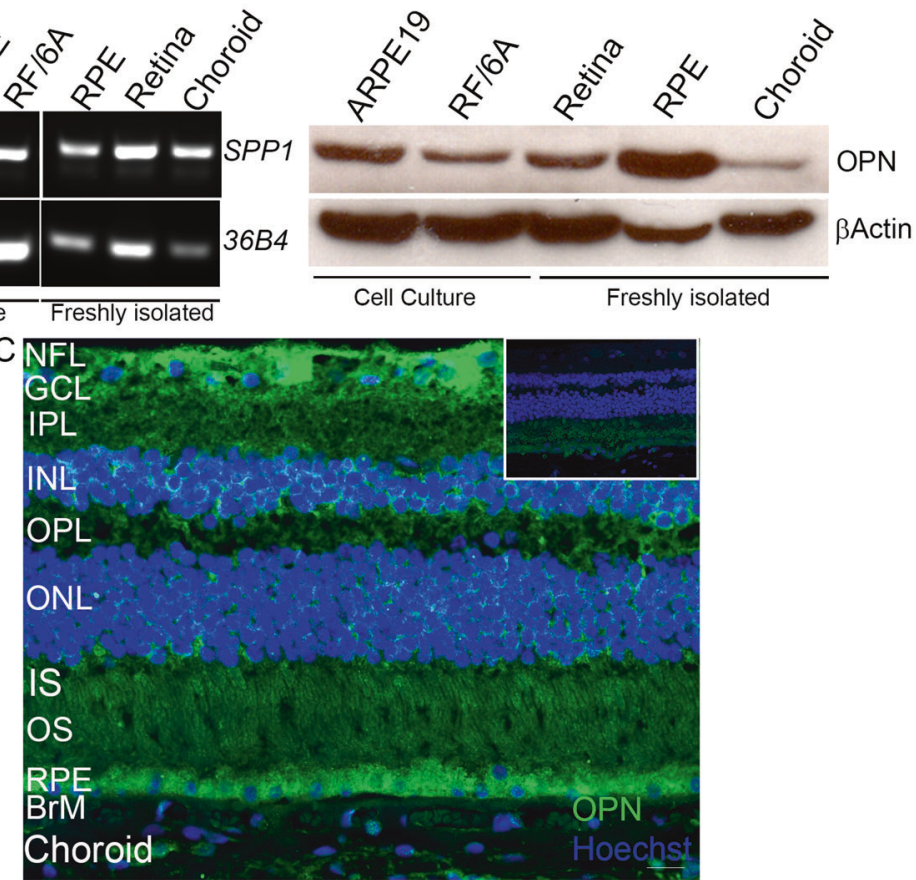

Fig. 1 OPN is expressed in cells of the posterior retina and human donor eyes. A Real-time PCR of the SPP1 gene (OPN) in ARPE19, primary RPE cells (hRPE, 93-year-old, female donor), RF/6A cells, and freshly isolated RPE, retina, and choroid tissues from a 74-year-old, female donor. B Western blot showing OPN protein expression in ARPE19, RF/6A cells, and freshly isolated retina, RPE, and choroid. C Immunofluorescence staining of retinal sections from an aged non-AMD donor shows OPN expression throughout the retinal layers, RPE, and choroid (Scale bar $=$ $20 \mu \mathrm{m}$ ). No primary control is shown in the inset. (BrM Bruch's membrane, GCL ganglion cell layer, INL inner nuclear layer, IPL inner plexiform layer, IS photoreceptor inner segments, NFL nerve fiber layer, ONL outer nuclear layer, OPL outer plexiform layer, OS photoreceptor outer segments, RPE retinal pigment epithelial cells).

\section{OPN expression in early AMD}

Retinal cross-sections from donor eyes diagnosed with early-dry AMD were probed with the antibody to OPN and found to show OPN positive immunoreactivity throughout basal deposits, and drusen of various sizes. OPN positive staining was observed in spherules and were often punctate in nature within thin and thick diffuse basal deposits (Fig. 2A, B, C). Small hard drusen also contained punctate OPN immunoreactivity, presenting as large spherules with more well defined shapes (Fig. 2D, E, F). Noteworthy, is that a lower density of OPN spherules was observed in the hard druse compared to the thin and thick diffuse deposits (Fig. 2). OPN staining in the RPE overlying basal deposits varied with punctate staining present primarily in RPE overlying drusen (Fig. 2C, E, F, H) and less so above basal laminar deposits (Fig. 2A, B). Examination of medium-large sized (Fig. 2G, $\mathrm{H})$, revealed a larger concentration of OPN positive spherules within large drusen. Overall, greater than $68 \%$ of drusen contained OPN positive spherules to some degree. These OPN positive spherules appeared to be well demarcated with a cross-sectional size ranging from 0.5 to $15 \mu \mathrm{m}$ in diameter. We also probed retinal sections from AMD donors with antibodies against known protein components of drusen and found that drusen showed positive staining for vitronectin (VTN) throughout the deposit, which did not co-localize with OPN (Fig. 3A). Similarly, apolipoprotein E (APOE) was observed to be diffuse throughout the druse and within the choriocapillary pegs (Fig. 3B), while complement factor $\mathrm{H}$ (CFH) localized within the RPE, druse, and the choroid and overlapped with OPN positive spherules (Fig. 3C). Finally, given the reported relationship between OPN and macrophage recruitment and retention, we examined the staining pattern of Iba-1, a microglia/macrophage calcium-binding $\operatorname{protein}^{58,62}$ relative to that of OPN. Iba-1 immunoreactivity was evident within the neural retina, the choriocapillaris, and adjacent to the RPE overlying drusen containing OPN positive puncta (Fig. 3D).

\section{OPN puncta localize within calcified drusen in donor AMD eyes}

OPN is aspartic acid-rich, which makes it a highly acidic protein. This feature, combined with the presence of putative calcium $\left(\mathrm{Ca}^{2+}\right)$ binding motifs, allows it to bind large amounts of $\mathrm{Ca}^{2+}$ and to interact with hydroxyapatite crystals with high affinity ${ }^{63}$. Moreover, calcification in drusen has been identified in AMD-affected eyes by multiple modalities and has been associated with disease progression $^{64-66}$. We examined the relative staining pattern of OPN within calcified drusen in AMD donor eye tissue by staining adjacent paraffin sections ( $\sim 25 \mu \mathrm{m}$ apart) probed for OPN, with the VonKossa histochemical stain. We found that whereas non-AMD eyes did not display any calcified particles in the posterior retina (data not shown), extensive calcifications were seen throughout large drusen in a punctate manner similar to the OPN spherules, suggesting a possible role of OPN in accumulation of $\mathrm{Ca}^{2+}$ ions in the drusen (Fig. 3E).

\section{AMD-relevant stressors can stimulate OPN secretion from RPE cells}

To determine mechanisms that may underly extracellular deposition of OPN from RPE cells, we tested the ability of hRPE cells to secrete OPN following exposure to AMD-stressors. Of the three hRPE cells lines tested, RPE cells derived from the 93-year-old donor were found to be capable of secreting OPN protein, as measured by ELISA, in response to selective injury sublethal treatments including the oxidants, cigarette-smoke extract (CSE; $2.7 \mathrm{ng} / \mathrm{ml}$ ) and hydroquinone ( $\mathrm{HQ}: 4.3 \mathrm{ng} / \mathrm{ml})$, and the omega fatty acid, docosahexaenoic acid (DHA; $2.5 \mathrm{ng} / \mathrm{ml}$; Fig. 4A). Sublethal 

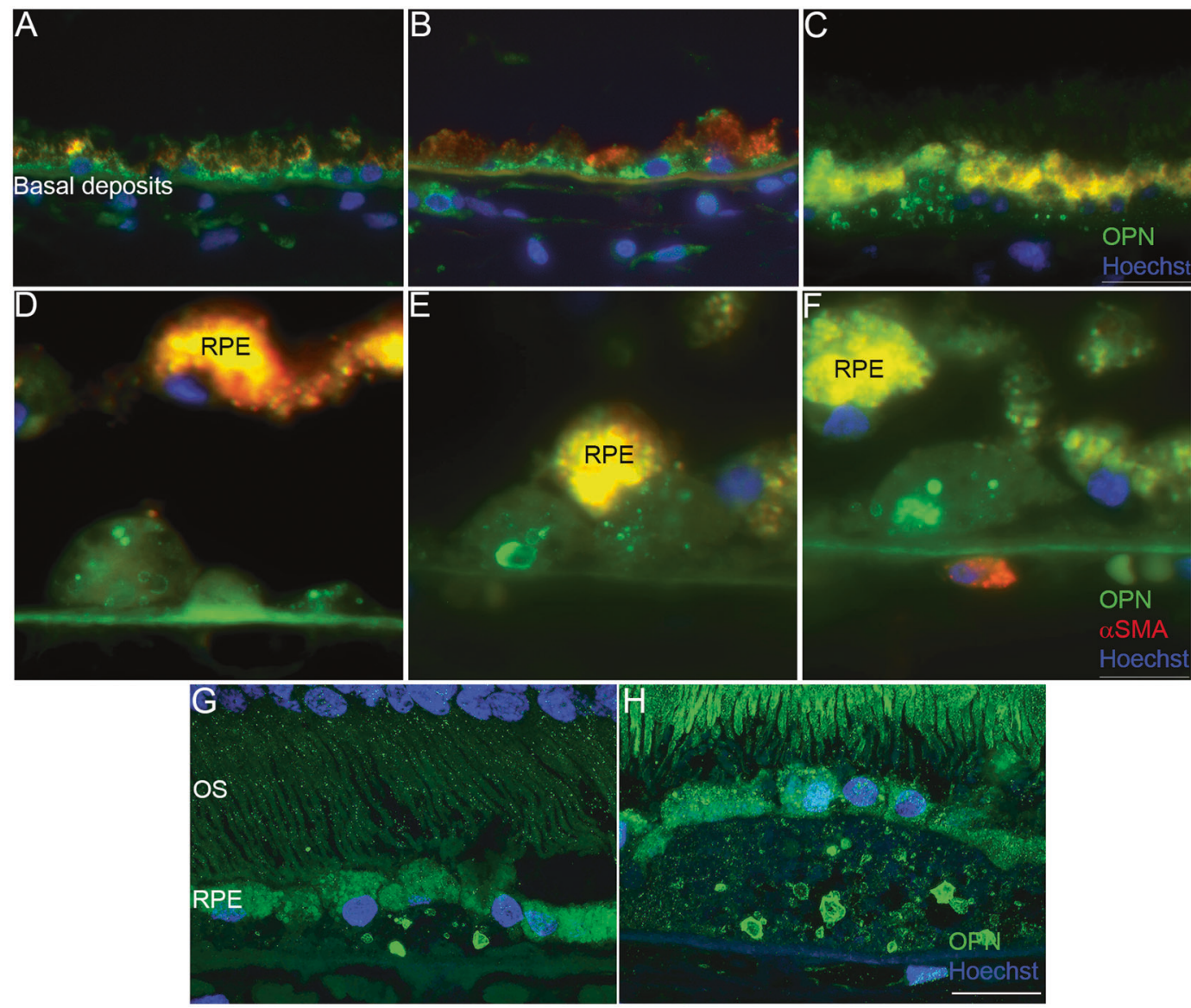

Fig. 2 OPN immunoreactivity within basal deposits. A, B, C Immunofluorescence staining of human AMD donor eyes showing OPN puncta within diffuse basal deposits and RPE cells. D, E, F, G, H High magnification images of AMD donor eyes showing punctate OPN staining within small- and medium-sized drusen. Scale bar $(\mathbf{C}, \mathbf{H})=20 \mu \mathrm{m}$, Scale bar $(\mathbf{F})=40 \mu \mathrm{m}$ (OS photoreceptor outer segments, RPE retinal pigment epithelial cells). OPN green in (A-H); $\alpha$-smooth muscle actin: red in (A-F).

levels of the treatments were confirmed by morphology and cell viability assessments (Supplementary Figs. 4, 4B). The baseline levels of OPN secretion from the other two cells lines derived from a 48 year old and 84 year old were close to zero. Sublethal injury of the young cell line with AMD-risk factors did not induce OPN secretion, while treatment with cigarette-smoke extract and hydroquinone was able to stimulate a low level of OPN secretion ( 0.54 and $0.6 \mathrm{ng} / \mathrm{ml}$, respectively) from the RPE cells collected from the 84 year old. These findings while highlighting subjective differences in response to injury, support that aged RPE cells may be a local ocular source of OPN and that select AMD-risk factors are capable of triggering OPN secretion from RPE cells leading it its accumulation in basal deposits.

\section{Plasma OPN levels increase in human donors as a function of age}

To determine if systemic OPN levels vary with age and AMD disease status, we measured OPN concentrations in plasma collected from human donors. We found that non-AMD donors exhibited an agerelated increase in systemic OPN levels as a function of age. Noteworthy, however is that only three individuals in the aged group showed elevated OPN levels $(>235 \mathrm{ng} / \mathrm{ml})$, resulting in a statistically significant difference (Fig. 5). We did not observe any significant differences in OPN levels as a function of severity of disease in AMD patients with early, intermediate, and neovascular AMD. Intermediate AMD and CNV showed a trend towards a drop in OPN levels, though this was most likely due to a few aged donors with elevated circulating OPN levels.

\section{DISCUSSION}

Much of our understanding of the pathology of ocular diseases such as AMD, in recent years, has relied on OCT imaging of patients ${ }^{67,68}$. However, evaluation of postmortem ocular tissue remains the gold standard for ascertaining biochemical composition and protein localization in tissue and subcellular regions. Through histochemistry and immunohistochemistry many of the components of basal deposits, characteristic lesions of early AMD, which are also risk factors for progression of AMD, have been identified to date, including but not limited to, esterified and unesterified cholesterol, cholesterol carriers including apolipoproteins, clusterin, vitronectin, components of the complement pathway, and proteoglycans ${ }^{11,22,66,69,70}$. Knowledge of these molecules, in turn, have led to confirmatory support for genetic risk factors identified and/or have revealed pathogenic pathways that may be involved in the initiation and progression of $\mathrm{AMD}$, including inflammation, dysregulation of lipid transport and processing, and alternations in extracellular matrix homeostasis, thus underscoring the value of identifying tissue biomarkers of early AMD.

Herein we identified and localized the phosphoprotein, OPN, within the inner and outer human retina and discovered it to be a component of basal deposits. We also observed that though this inflammatory mediator's punctate pattern parallels that of calcification and complement factor $\mathrm{H}$ in drusen and basal laminar deposits of a variety of sizes, it does not co-localize with other known drusen components including apolipoprotein $\mathrm{E}$ and vitronectin, which are diffusely spread throughout the deposits ${ }^{22}$. Furthermore, we examined potential local mechanisms contributing to extracellular 

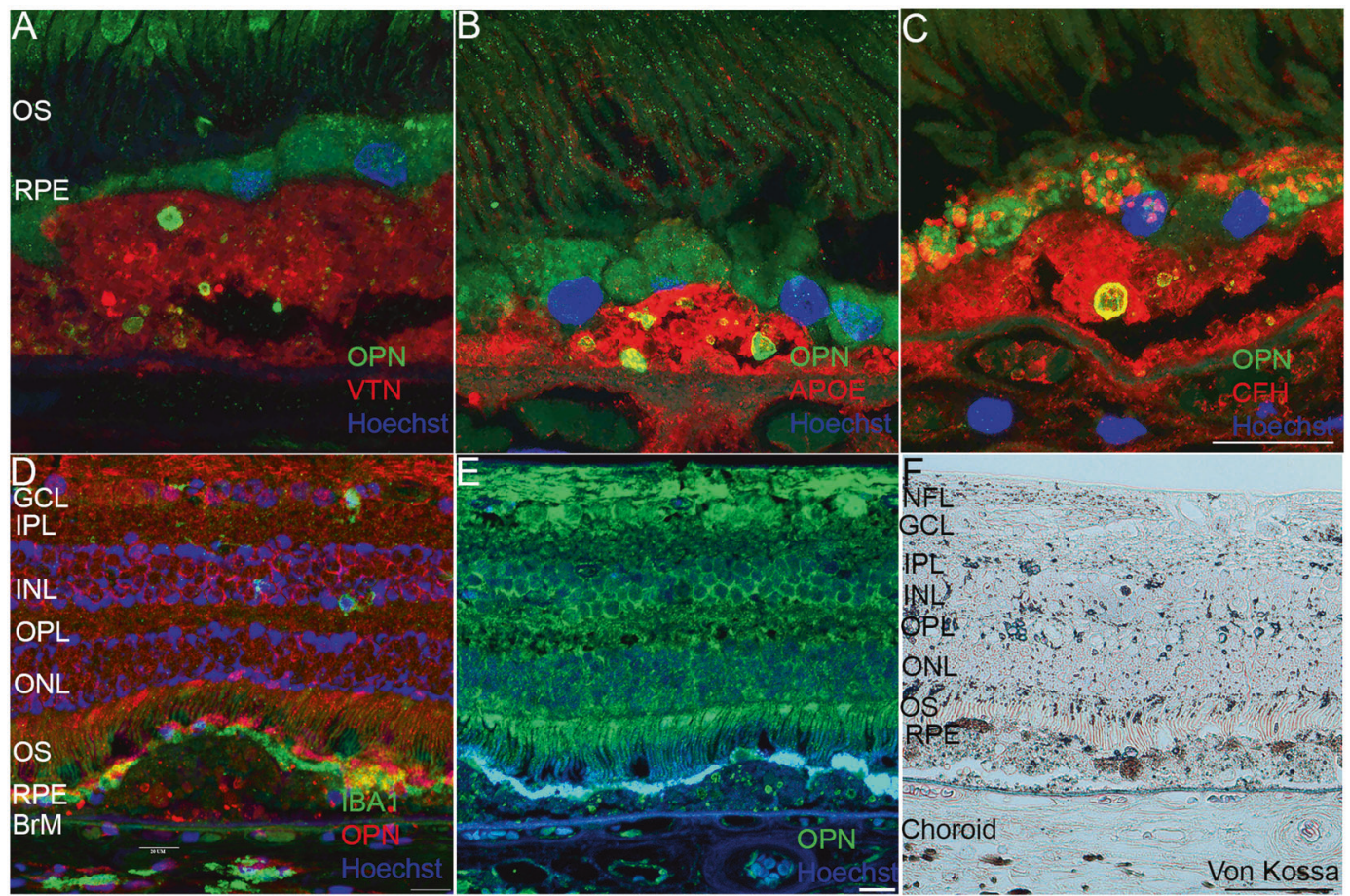

Fig. 3 Colocalization of OPN with known drusen components. Immunofluorescence staining of AMD human donor eyes showing the OPN (green) puncta pattern in drusen relative to (A) Vitronectin (VTN: red), (B) Apolipoprotein E (APOE: red), and (C) Complement Factor H (CFH: red). Scale bar in (C) $=20 \mu \mathrm{m}$. (D) OPN immunoreactivity (red) versus the distribution of the microglial marker IBA1 (green) throughout the full neurosensory retina, RPE, and choroid. E OPN immunoreactivity (green) (Scale bar $=20 \mu \mathrm{m}$ ) and (F) Von-Kossa staining of serial cross-sections $\sim 25 \mu \mathrm{m}$ apart from an AMD human donor eye, showing calcification (black) and counterstained nuclei (pink). (Scale bar $=20 \mu \mathrm{m})$. BrM Bruch's membrane, GCL ganglion cell layer, INL inner nuclear layer, IPL inner plexiform layer, NFL nerve fiber layer, ONL outer nuclear layer, OPL outer plexiform layer, OS photoreceptor outer segments, RPE retinal pigment epithelium.
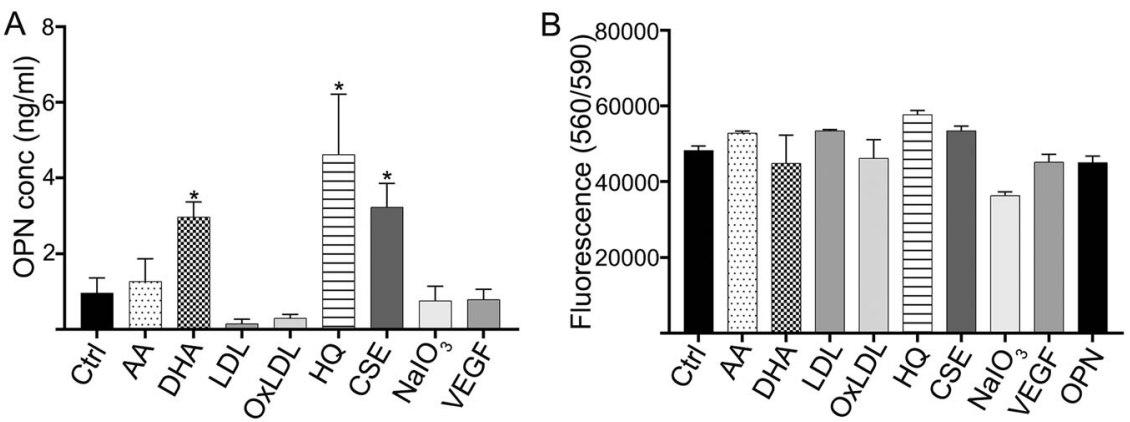

Fig. 4 Extracellular OPN levels secreted from human primary RPE cells in response to AMD-risk factors. (A) OPN levels were measured by ELISA in media collected from human primary RPE cells, from a 93-year-old donor, treated with AMD-risk factors. ${ }^{*} p<0.05, n=3,0$ One-way ANOVA, multiple comparisons). (B) Cell viability of hRPE cells in response to treatment. (AA arachidonic acid, DHA docosahexaenoic acid, LDL low-density lipoprotein, OxLDL oxidized LDL, CSE cigarette-smoke extract, HQ hydroquinone, NalO3 sodium iodate, VEGF vascular endothelial growth factor.

deposition of OPN and found AMD-associated risk factors including oxidant injury and lipid challenge, capable of upregulating OPN secretion from RPE cells derived from aged donors. Finally, while systemically OPN levels varied with advanced age, no differences were detected based on disease clinical sub-type.

Inflammation and the recruitment of immune cells creating a pro-inflammatory microenvironment in the subretinal space, have consistently been implicated in the development and progression of $A M D^{13,71-73}$. Our discovery of OPN as potential tissue biomarker of $A M D$, since it accumulates in extracellular lesions characteristic of early AMD, further supports the reported role that inflammation plays in the pathogenesis of the disease. However, the role of OPN in the posterior segment of the eye may not be limited to inflammation as it has also been implicated in fibrosis and chemotaxis $^{74,75}$, raising the possibility that extracellular OPN accumulation may reflect RPE differentiation (epithelial-tomesenchymal transition) ${ }^{32}$, as OPN was originally identified as a secreted protein from transformed epithelial cells ${ }^{76}$. Importantly, the presence of OPN in the choroid may hint to its involvement in not only macrophage recruitment, but also endothelial-tomesenchymal transition and/or endothelial migration ${ }^{32,77}$. Though exposure to vascular endothelial growth factor (VEGF) in RPE cells in culture in our study did not result in elevated OPN, there are studies that indicate OPN can promote angiogenesis and endothelial migration though PI3K/AKT pathways with VEGF acting as a positive feedback signal ${ }^{78}$.

Mechanistically, another physiological responsibility of OPN is control of biomineralization, through its ability to bind apatite 

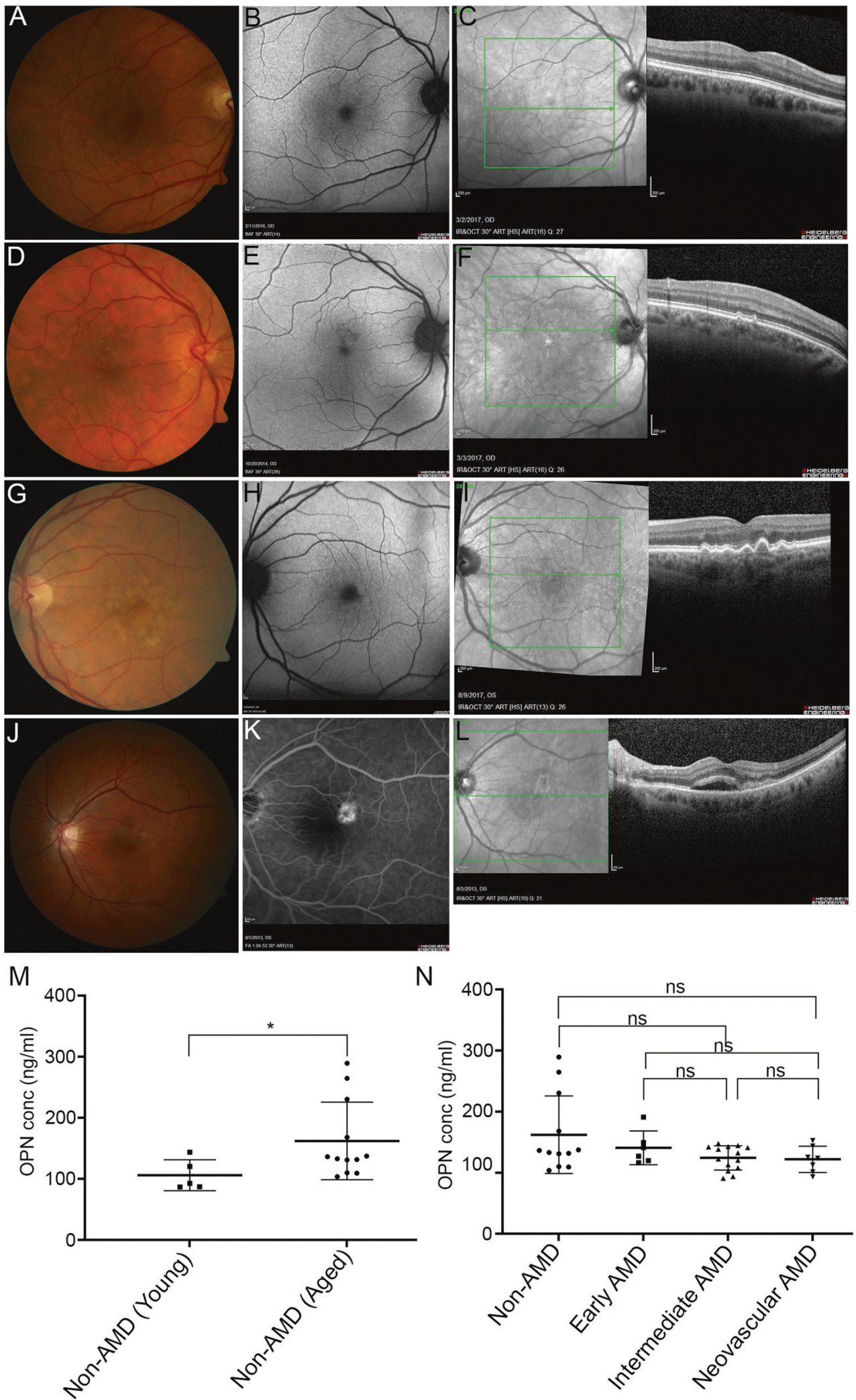

Fig. 5 Systemic OPN levels in AMD patients. Representative donor fundus photos (A, D, G, J), fundus autofluorescence (B, E, $\mathbf{H}, \mathbf{K})$, and OCT images (C, F, I, L) for different AMD disease stages; (A, B, C) Non-AMD (Aged), (D, E, F) Early AMD, (G, H, I) Intermediate AMD, and (J, K, L) Neovascular AMD (Scale bar $=200 \mu \mathrm{m}$ ). Plasma OPN levels measured by ELISA in plasma of (M) Non-AMD (Aged) versus Non-AMD (Young) and (N) AMD patients classified as early, intermediate, and neovascular AMD with choroidal neovascularization. ( ${ }^{*} p<0.05$, One-way ANOVA, Sidak's multiple comparisons). 
crystals $^{31}$. OPN knockout mice reportedly present with hypermineralized and fragile bones ${ }^{79}$. Moreover, OPN has been shown to accumulate and co-localize in regions with pathological calcification in atherosclerotic lesions, aortic stenosis, kidney stones, and the vasculature ${ }^{34,63,80,81}$. Of relevance to $A M D$, are studies demonstrating the accumulation of hydroxyapatite spherules within drusen ${ }^{82}$, in a similar pattern to that of OPN as observed in our study. We also made the observation that OPN puncta were found in calcified drusen, an indicator of AMD progression ${ }^{65,83-85}$. OPN contains an integrin binding arginine-glycine-aspartate (RGD) motif and aspartic-acid rich calcium-binding domains, which may facilitate its localization and accumulation in drusen, as drusen itself is a conglomerate of lipids and proteins. In fact, vitronectin, a well-established marker of drusen ${ }^{86}$, contains RGD motifs, as well as calcium rich hydroxyapatite ${ }^{65,82}$, thus providing OPN a framework and the physical forces required for its build up and accumulation. The complex physical interactions of OPN and drusen components need to be investigated thoroughly to further tease out the molecular crosstalk in deposits.

There is evidence for both local and systemic sources of OPN based on studies of a variety of tissues and cells including macrophages, activated microglia, astrocytes and epithelial cells $^{33,87-92}$, as well as neurodegenerative diseases such as multiple sclerosis, Alzheimer's disease, Parkinson's disease, and ischemic stroke ${ }^{53,91,93-97}$. In the human donor eyes, OPN expression was detected in freshly isolated tissue from RPE, choroid, and retina, suggesting multiple tissues in the posterior retina express, and have the potential to secrete OPN. Challenging primary human RPE cells from aged donors in culture with AMD-relevant stressors, supported select oxidative insults including cigarettesmoke extract and hydroquinone, as well as increased lipid burden as potential inducers of OPN secretion, locally. The triggers for OPN secretion by other retinal cells remain to be identified. Though the role of OPN is tissue specific, these results are congruent with mouse studies in which OPN levels have been shown to increase during the onset of drug-induced liver injury ${ }^{98}$.

The levels of OPN in systemic circulation were also measured and found to increase with aging in the plasma. Noteworthy, was the presence of two populations in the aged group, one in which OPN levels were similar to the young donors, and the other in which OPN levels were elevated. The small cohort size of donors in our study is a limitation and it is plausible that with a larger cohort, this potential difference may be evaluated further and allow for correlation studies taking into consideration the inflammatory status of the two groups and testing the hypothesis that in a subpopulation of individuals, OPN may be transported via the choroidal circulation to the sub-RPE space. Interestingly, when OPN levels were measured as a function of AMD progression, statistically significant differences were not detected and in fact the levels were similar to that of young donors. Overall, though it is possible that an additional source of OPN may come from the circulation, our findings so far are supportive of local OPN production.

Our discovery of large numbers of OPN immunopositive puncta in deposits characteristic of AMD, is a novel finding, however the function of OPN in the sub-RPE space remains to be fully elucidated. On the one hand it has been suggested that OPN has neuroprotective and repair-promoting effects in neurodegenerative diseases such as Alzheimer's disease and considering the parallels between AMD and neurodegenerative diseases, it is possible that OPN might be induced and secreted from RPE cells in a last-ditch effort to preserve its function ${ }^{99-101}$. On the other hand, OPN secretion might serve as a cytokine, which is involved in the recruitment of activated microglia/macrophages in the immune-privileged subretinal space in response to oxidative injury to the RPE cells. Understanding the distribution of the alternative splicing products of the human OPN, which generates three different isoforms (OPNa, OPNb, and OPNc) will also be important, as these isoforms contribute to the variable expressions and functional properties of OPN in different pathophysiological conditions. Additionally, though in humans, most studies on OPN have primarily focused on the secreted protein, OPN is also known to undergo posttranslational modifications and the role of intracellular OPN in RPE cells remains to be considered. Finally, future studies focused on the role of OPN in the choroid and retina, tissues also vulnerable in AMD, along with animal models in which local OPN levels have been altered will be necessary in order to shed further light on the role of OPN in drusen biogenesis, RPE cell function, and AMD progression.

\section{DATA AVAILABILITY}

The datasets used and/or analyzed during the current study are available from the corresponding author on reasonable request.

\section{REFERENCES}

1. DeAngelis, M. M. et al. Genetics of age-related macular degeneration (AMD). Hum. Mol. Genet. 26, R246 (2017).

2. Li, J. Q. et al. Prevalence and incidence of age-related macular degeneration in Europe: a systematic review and meta-analysis. Br. J. Ophthalmol. 104, 1077-1084 (2020).

3. Jonas, J. B., Cheung, C. M. G. \& Panda-Jonas, S. Updates on the epidemiology of age-related macular degeneration. Asia Pac. J. Ophthalmol. 6, 493-497 (2017).

4. Hassell, J. B., Lamoureux, E. L. \& Keeffe, J. E. Impact of age related macular degeneration on quality of life. Br. J. Ophthalmol. 90, 593-596 (2006).

5. Taylor, D. J., Hobby, A. E., Binns, A. M. \& Crabb, D. P. How does age-related macular degeneration affect real-world visual ability and quality of life? A systematic review. BMJ Open 6, e011504 (2016).

6. Li, C. M. et al. Lipoprotein-like particles and cholesteryl esters in human Bruch's membrane: initial characterization. Investig. Ophthalmol. Vis. Sci. 46, 2576-2586 (2005).

7. Malek, G. \& Lad, E. M. Emerging roles for nuclear receptors in the pathogenesis of age-related macular degeneration. Cell. Mol. Life Sci. 71, 4617-4636 (2014).

8. Curcio, C. A., Johnson, M., Huang, J. D. \& Rudolf, M. Apolipoprotein B-containing lipoproteins in retinal aging and age-related macular degeneration. J. Lipid Res. 51, 451-467 (2010).

9. Tarau, I. S., Berlin, A., Curcio, C. A. \& Ach, T. The cytoskeleton of the retinal pigment epithelium: from normal aging to age-related macular degeneration. Int. J. Mol. Sci. 20 (2019).

10. Lakkaraju, A. et al. The cell biology of the retinal pigment epithelium. Prog. Retin. Eye Res. https://doi.org/10.1016/j.preteyeres.2020.100846 100846 (2020).

11. Curcio, C. A., Presley, J. B., Millican, C. L. \& Medeiros, N. E. Basal deposits and drusen in eyes with age-related maculopathy: evidence for solid lipid particles. Exp. Eye Res. 80, 761-775 (2005).

12. Sura, A. A. et al. Measuring the Contributions of basal laminar deposit and bruch's membrane in age-related macular degeneration. Investig. Ophthalmol. Vis. Sci. 61, 19 (2020).

13. Ambati, J. \& Fowler, B. J. Mechanisms of age-related macular degeneration. Neuron 75, 26-39 (2012)

14. Holekamp, N. M. Review of neovascular age-related macular degeneration treatment options. Am. J. Manag. Care 25, S172-S181 (2019).

15. Miller, J. W., Bagheri, S. \& Vavvas, D. G. Advances in age-related macular degeneration understanding and therapy. US Ophthalmic Rev. 10, 119-130 (2017).

16. Mitchell, P., Liew, G., Gopinath, B. \& Wong, T. Y. Age-related macular degeneration. Lancet 392, 1147-1159 (2018).

17. Liu, K. \& Xie, B. Today and future of age-related macular degeneration. ISRN Ophthalmol. 2012, 480212 (2012).

18. Fritsche, L. G. et al. A large genome-wide association study of age-related macular degeneration highlights contributions of rare and common variants. Nat. Genet. 48, 134-143 (2016).

19. Han, X. et al. Genome-wide meta-analysis identifies novel loci associated with age-related macular degeneration. J. Hum. Genet. 65, 657-665 (2020).

20. Handa, J. T. et al. A systems biology approach towards understanding and treating non-neovascular age-related macular degeneration. Nat. Commun. 10, 3347 (2019).

21. Russell, S. R., Mullins, R. F., Schneider, B. L. \& Hageman, G. S. Location, substructure, and composition of basal laminar drusen compared with drusen associated with aging and age-related macular degeneration. Am. J. Ophthalmol. 129, 205-214 (2000) 
22. Wang, L. et al. Abundant lipid and protein components of drusen. PLOS ONE $\mathbf{5}$, e10329 (2010)

23. Crabb, J. W. The proteomics of drusen. Cold Spring Harb. Perspect. Med. 4 a017194 (2014).

24. Ebrahimi, K. B. \& Handa, J. T. Lipids, lipoproteins, and age-related macular degeneration. J. Lipids 2011, 802059 (2011).

25. Johnson, L. V., Leitner, W. P., Staples, M. K. \& Anderson, D. H. Complement activation and inflammatory processes in Drusen formation and age related macular degeneration. Exp. Eye Res. 73, 887-896 (2001).

26. Chen, M. \& Xu, H. Parainflammation, chronic inflammation, and age-related macular degeneration. J. Leukoc. Biol. 98, 713-725 (2015).

27. Tan, P. L., Bowes Rickman, C. \& Katsanis, N. AMD and the alternative complement pathway: genetics and functional implications. Hum. Genom. 10, 23 (2016).

28. Toomey, C. B., Johnson, L. V. \& Bowes Rickman, C. Complement factor H in AMD: bridging genetic associations and pathobiology. Prog. Retin. Eye Res. 62, 38-57 (2018).

29. Lenga, Y. et al. Osteopontin expression is required for myofibroblast differentiation. Circ. Res. 102, 319-327 (2008).

30. Rittling, S. R. Osteopontin in macrophage function. Expert Rev. Mol. Med. 13, e15 (2011).

31. Scatena, M., Liaw, L. \& Giachelli, C. M. Osteopontin: a multifunctional molecule regulating chronic inflammation and vascular disease. Arterioscler. Thromb. Vasc. Biol. 27, 2302-2309 (2007).

32. Kothari, A. N. et al. Osteopontin-A master regulator of epithelial-mesenchymal transition. J. Clin. Med. 5 (2016).

33. Brown, L. F. et al. Expression and distribution of osteopontin in human tissues: widespread association with luminal epithelial surfaces. Mol. Biol. Cell. 3, 1169-1180 (1992)

34. Zhao, H. et al. The role of osteopontin in the progression of solid organ tumour. Cell Death Dis. 9, 356 (2018).

35. Chidlow, G., Wood, J. P., Manavis, J., Osborne, N. N. \& Casson, R. J. Expression of osteopontin in the rat retina: effects of excitotoxic and ischemic injuries. Investig. Ophthalmol. Vis. Sci. 49, 762-771 (2008).

36. Schlecht, A. et al. Secreted phosphoprotein 1 expression in retinal mononuclear phagocytes links murine to human choroidal neovascularization. Front. Cell Dev. Biol. 8, 618598 (2020).

37. Voigt, A. P. et al. Single-cell transcriptomics of the human retinal pigment epithelium and choroid in health and macular degeneration. Proc. Natl Acad. Sci. U. S.A. 116, 24100-24107 (2019).

38. Hollborn, M., Bruck, R., Kuhrt, H., Wiedemann, P. \& Bringmann, A. Osmotic and hypoxic induction of osteopontin in retinal pigment epithelial cells: Involvement of purinergic receptor signaling. Mol. Vis. 26, 188-203 (2020).

39. Farnoodian, M., Sorenson, C. M. \& Sheibani, N. PEDF expression affects the oxidative and inflammatory state of choroidal endothelial cells. Am. J. Physiol. Cell Physiol. 314, C456-C472 (2018).

40. Maziere, C., Gomila, C. \& Maziere, J. C. Oxidized low-density lipoprotein increases osteopontin expression by generation of oxidative stress. Free Radic. Biol. Med. 48, 1382-1387 (2010).

41. Icer, M. A. \& Gezmen-Karadag, M. The multiple functions and mechanisms of osteopontin. Clin. Biochem. 59, 17-24 (2018).

42. Lok, Z. S. Y. \& Lyle, A. N. Osteopontin in vascular disease. Arterioscler. Thromb. Vasc. Biol. 39, 613-622 (2019).

43. Wolak, T. Osteopontin-a multi-modal marker and mediator in atherosclerotic vascular disease. Atherosclerosis 236, 327-337 (2014).

44. Holm, E. et al. Osteopontin mediates mineralization and not osteogenic cell development in vitro. Biochem. J. 464, 355-364 (2014).

45. Carecchio, M. \& Comi, C. The role of osteopontin in neurodegenerative diseases. J. Alzheimers Dis. 25, 179-185 (2011).

46. Chabas, D. et al. The influence of the proinflammatory cytokine, osteopontin, on autoimmune demyelinating disease. Science 294, 1731-1735 (2001).

47. Giachelli, C. M., Liaw, L., Murry, C. E., Schwartz, S. M. \& Almeida, M. Osteopontin expression in cardiovascular diseases. Ann. N. Y. Acad. Sci. 760, 109-126 (1995).

48. O'Brien, E. R. et al. Osteopontin is synthesized by macrophage, smooth muscle, and endothelial cells in primary and restenotic human coronary atherosclerotic plaques. Arterioscler. Thromb. 14, 1648-1656 (1994).

49. Kwon, H. M. et al. Expression of osteopontin in calcified coronary atherosclerotic plaques. J. Korean Med. Sci 15, 485-493 (2000).

50. Rollo, E. E., Laskin, D. L. \& Denhardt, D. T. Osteopontin inhibits nitric oxide production and cytotoxicity by activated RAW264.7 macrophages. J. Leukoc. Biol. 60, 397-404 (1996).

51. Wai, P. Y. et al. Osteopontin inhibits macrophage nitric oxide synthesis to enhance tumor proliferation. Surgery 140, 132-140 (2006)

52. Gao, C., Guo, H., Mi, Z., Grusby, M. J. \& Kuo, P. C. Osteopontin induces ubiquitindependent degradation of STAT1 in RAW264.7 murine macrophages. J. Immunol. 178, 1870-1881 (2007)
53. Comi, C. et al. Osteopontin is increased in the cerebrospinal fluid of patients with Alzheimer's disease and its levels correlate with cognitive decline. J. Alzheimers Dis. 19, 1143-1148 (2010).

54. Denhardt, D. T., Noda, M., O'Regan, A. W., Pavlin, D. \& Berman, J. S. Osteopontin as a means to cope with environmental insults: regulation of inflammation, tissue remodeling, and cell survival. J. Clin. Investig. 107, 1055-1061 (2001).

55. Hu, P. et al. Aryl hydrocarbon receptor deficiency causes dysregulated cellular matrix metabolism and age-related macular degeneration-like pathology. Proc. Natl Acad. Sci. U.S.A. 110, E4069-E4078 (2013).

56. Choudhary, M. et al. PPARbeta/delta selectively regulates phenotypic features of age-related macular degeneration. Aging 8, 1952-1978 (2016).

57. Dwyer, M. A., Kazmin, D., Hu, P., McDonnell, D. P. \& Malek, G. Research resource: nuclear receptor atlas of human retinal pigment epithelial cells: potential relevance to age-related macular degeneration. Mol. Endocrinol. 25, 360-372 (2011).

58. Choudhary, M. et al. Aryl hydrocarbon receptor knock-out exacerbates choroidal neovascularization via multiple pathogenic pathways. J. Pathol. 235, 101-112 (2015).

59. Choudhary, M. et al. LXRs regulate features of age-related macular degeneration and may be a potential therapeutic target. JCl Insight 5 (2020).

60. Choudhary, M., Safe, S. \& Malek, G. Suppression of aberrant choroidal neovascularization through activation of the aryl hydrocarbon receptor. Biochim. Biophys. Acta Mol. Basis Dis. 1864, 1583-1595 (2018).

61. Carp, H. \& Janoff, A. Possible mechanisms of emphysema in smokers. In vitro suppression of serum elastase-inhibitory capacity by fresh cigarette smoke and its prevention by antioxidants. Am. Rev. Respir. Dis. 118, 617-621 (1978).

62. Zhou, T. et al. Microglia polarization with M1/M2 phenotype changes in rd1 mouse model of retinal degeneration. Front. Neuroanat. 11, 77 (2017).

63. Giachelli, C. M., Schwartz, S. M. \& Liaw, L. Molecular and cellular biology of osteopontin potential role in cardiovascular disease. Trends Cardiovasc. Med. 5, 88-95 (1995).

64. van der Schaft, T. L., de Bruijn, W. C., Mooy, C. M., Ketelaars, D. A. \& de Jong, P. T. Element analysis of the early stages of age-related macular degeneration. Arch. Ophthalmol. 110, 389-394 (1992).

65. Tan, A. C. S. et al. Calcified nodules in retinal drusen are associated with disease progression in age-related macular degeneration. Sci. Transl. Med. 10 (2018).

66. Spraul, C. W. \& Grossniklaus, H. E. Characteristics of Drusen and Bruch's membrane in postmortem eyes with age-related macular degeneration. Arch. Ophthalmol. 115, 267-273 (1997).

67. Gamulescu, M. A., Panagakis, G., Theek, C. \& Helbig, H. Predictive factors in OCT analysis for visual outcome in exudative AMD. J. Ophthalmol. 2012, 851648 (2012).

68. Keane, P. A. et al. Evaluation of age-related macular degeneration with optical coherence tomography. Surv. Ophthalmol. 57, 389-414 (2012).

69. Curcio, C. A. Imaging maculopathy in post-mortem human eyes. Vis. Res. 45 , 3496-3503 (2005)

70. Geerlings, M. J., de Jong, E. K. \& den Hollander, A. I. The complement system in age-related macular degeneration: $A$ review of rare genetic variants and implications for personalized treatment. Mol. Immunol. 84, 65-76 (2017).

71. Kauppinen, A., Paterno, J. J., Blasiak, J., Salminen, A. \& Kaarniranta, K. Inflammation and its role in age-related macular degeneration. Cell. Mol. Life Sci. 73, 1765-1786 (2016).

72. Curcio, C. A. \& Huisingh, C. Probing the role of inflammation in age-related macular degeneration. JAMA Ophthalmol. 135, 843-844 (2017).

73. Yu, C., Roubeix, C., Sennlaub, F. \& Saban, D. R. Microglia versus monocytes: distinct roles in degenerative diseases of the retina. Trends Neurosci. 43, 433-449 (2020).

74. Lund, S. A., Giachelli, C. M. \& Scatena, M. The role of osteopontin in inflammatory processes. J. Cell Commun. Signal. 3, 311-322 (2009).

75. Mori, R., Shaw, T. J. \& Martin, P. Molecular mechanisms linking wound inflammation and fibrosis: knockdown of osteopontin leads to rapid repair and reduced scarring. J. Exp. Med. 205, 43-51 (2008).

76. Senger, D. R., Wirth, D. F. \& Hynes, R. O. Transformed mammalian cells secrete specific proteins and phosphoproteins. Cell 16, 885-893 (1979).

77. Poggio, P. et al. Osteopontin controls endothelial cell migration in vitro and in excised human valvular tissue from patients with calcific aortic stenosis and controls. J. Cell. Physiol. 226, 2139-2149 (2011).

78. Dai, J. et al. Osteopontin induces angiogenesis through activation of PI3K/AKT and ERK1/2 in endothelial cells. Oncogene 28, 3412-3422 (2009).

79. Boskey, A. L., Spevak, L., Paschalis, E., Doty, S. B. \& McKee, M. D. Osteopontin deficiency increases mineral content and mineral crystallinity in mouse bone. Calcif. Tissue Int. 71, 145-154 (2002).

80. Berezin, A. E. \& Kremzer, A. A. Circulating osteopontin as a marker of early coronary vascular calcification in type two diabetes mellitus patients with known asymptomatic coronary artery disease. Atherosclerosis 229, 475-481 (2013). 
81. Hirose, M. et al. Role of osteopontin in early phase of renal crystal formation: immunohistochemical and microstructural comparisons with osteopontin knock-out mice. Urol. Res. 40, 121-129 (2012).

82. Thompson, R. B. et al. Identification of hydroxyapatite spherules provides new insight into subretinal pigment epithelial deposit formation in the aging eye. Proc. Natl Acad. Sci. U.S.A. 112, 1565-1570 (2015).

83. Bressler, N. M., Silva, J. C., Bressler, S. B., Fine, S. L. \& Green, W. R. Clinicopathologic correlation of drusen and retinal pigment epithelial abnormalities in age-related macular degeneration. Retina 14, 130-142 (1994).

84. Green, W. R. \& Key, S. N. 3rd Senile macular degeneration: a histopathologic study. 1977. Retina 25, 180-250 (2005). discussion 250-184.

85. Gass, J. D. Pathogenesis of disciform detachment of the neuroepithelium. Am. J. Ophthalmol. 63(Suppl), 1-139 (1967).

86. Hageman, G. S., Mullins, R. F., Russell, S. R., Johnson, L. V. \& Anderson, D. H. Vitronectin is a constituent of ocular drusen and the vitronectin gene is expressed in human retinal pigmented epithelial cells. FASEB J. 13, 477-484 (1999).

87. Wirths, $\mathrm{O}$. et al. Inflammatory changes are tightly associated with neurodegeneration in the brain and spinal cord of the APP/PS1KI mouse model of Alzheimer's disease. Neurobiol. Aging 31, 747-757 (2010).

88. Choi, J. S., Kim, H. Y., Cha, J. H., Choi, J. Y. \& Lee, M. Y. Transient microglial and prolonged astroglial upregulation of osteopontin following transient forebrain ischemia in rats. Brain Res. 1151, 195-202 (2007).

89. Lee, M. Y. et al. Expression of osteopontin mRNA in developing rat brainstem and cerebellum. Cell Tissue Res. 306, 179-185 (2001).

90. Schroeter, M., Zickler, P., Denhardt, D. T., Hartung, H. P. \& Jander, S. Increased thalamic neurodegeneration following ischaemic cortical stroke in osteopontindeficient mice. Brain 129, 1426-1437 (2006).

91. Kim, M. D., Cho, H. J. \& Shin, T. Expression of osteopontin and its ligand, CD44, in the spinal cords of Lewis rats with experimental autoimmune encephalomyelitis. J. Neuroimmunol. 151, 78-84 (2004).

92. Zhang, Z. X. et al. Osteopontin expressed in tubular epithelial cells regulates NK cell-mediated kidney ischemia reperfusion injury. J. Immunol. 185, 967-973 (2010).

93. Hur, E. M. et al. Osteopontin-induced relapse and progression of autoimmune brain disease through enhanced survival of activated T cells. Nat. Immunol. 8, 74-83 (2007).

94. Maetzler, W. et al. Osteopontin is elevated in Parkinson's disease and its absence leads to reduced neurodegeneration in the MPTP model. Neurobiol. Dis. 25, 473-482 (2007).

95. Wung, J. K. et al. Increased expression of the remodeling- and tumorigenicassociated factor osteopontin in pyramidal neurons of the Alzheimer's disease brain. Curr. Alzheimer Res. 4, 67-72 (2007).

96. Ellison, J. A. et al. Osteopontin and its integrin receptor alpha(v)beta3 are upregulated during formation of the glial scar after focal stroke. Stroke 29, 1698-1706 (1998). discussion 1707.

97. Wang, X. et al. Delayed expression of osteopontin after focal stroke in the rat. J. Neurosci. 18, 2075-2083 (1998).

98. Urtasun, R. et al. Osteopontin, an oxidant stress sensitive cytokine, up-regulates collagen-I via integrin alpha(V)beta(3) engagement and PI3K/pAkt/NFkappaB signaling. Hepatology 55, 594-608 (2012).

99. Meller, R. et al. Neuroprotection by osteopontin in stroke. J. Cereb. Blood Flow Metab. 25, 217-225 (2005).

100. van Velthoven, C. T., Heijnen, C. J., van Bel, F. \& Kavelaars, A. Osteopontin enhances endogenous repair after neonatal hypoxic-ischemic brain injury. Stroke 42, 2294-2301 (2011).

101. Shin, Y. J. et al. Overlapping distribution of osteopontin and calcium in the ischemic core of rat brain after transient focal ischemia. J. Neurotrauma 29, 1530-1538 (2012).

\section{ACKNOWLEDGEMENTS}

We are grateful to the patients, the donors, and donor families for their generosity. We thank Dr. Alan Proia for providing clinical and autopsy information of donor eyes and valuable discussions, and Dr. Scott Cousins for early discussions on the pathobiology of wet AMD. We appreciate the technical support provided by Mr. Edwin Meade and Ms. Amanda Bednar.

\section{AUTHOR CONTRIBUTIONS}

M.L., M.C., and G.M. participated in the collection of samples and data, data analysis, and wrote the paper. E.M.L. assessed clinical diagnoses and oversaw collection of blood samples from normal and AMD patients. All authors read, edited, and approved the paper for publication.

\section{FUNDING}

This research was supported by the National Eye Institute grants R01 EY027802, R01 EY028160 (to G.M.), K23 EY026988 (to E.M.L.), P30 EY005722 (to the Duke Eye Center), Brightfocus Macular Degeneration Award (G.M.), and the Research to Prevent Blindness, Inc (RPB) Core grant (to the Duke Eye Center).

\section{COMPETING INTERESTS}

The authors declare no competing interests.

\section{ETHICS APPROVAL AND CONSENT TO PARTICIPATE}

Use of human donor eyes for research was approved by the Duke University Institutional Review Board (Exempt Review), and collected by either BioSight, the North Carolina Organ Donor and Eye Bank Inc., the Alabama Eye Bank, or through Duke Department of Pathology. Human donor blood samples were collected under a Duke approved Institutional Review Board protocol (\# Pro00063921).

\section{ADDITIONAL INFORMATION}

Supplementary information The online version contains supplementary material available at https://doi.org/10.1038/s41379-021-00887-7.

Correspondence and requests for materials should be addressed to G.M.

Reprints and permission information is available at http://www.nature.com/ reprints

Publisher's note Springer Nature remains neutral with regard to jurisdictional claims in published maps and institutional affiliations.

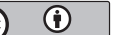

Open Access This article is licensed under a Creative Commons Attribution 4.0 International License, which permits use, sharing, adaptation, distribution and reproduction in any medium or format, as long as you give appropriate credit to the original author(s) and the source, provide a link to the Creative Commons license, and indicate if changes were made. The images or other third party material in this article are included in the article's Creative Commons license, unless indicated otherwise in a credit line to the material. If material is not included in the article's Creative Commons license and your intended use is not permitted by statutory regulation or exceeds the permitted use, you will need to obtain permission directly from the copyright holder. To view a copy of this license, visit http://creativecommons. org/licenses/by/4.0/.

(c) The Author(s) 2021 